\title{
Doações de campanha implicam em retornos contratuais futuros? Uma análise dos valores recebidos por empresas antes e após as eleições
}

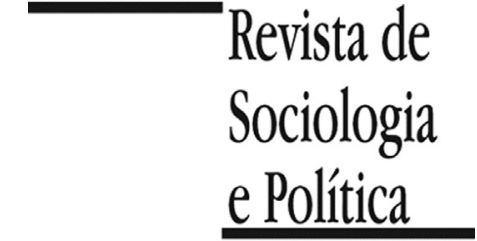

DOI 10.1590/1678-987317256103

\author{
Thiago do Nascimento Fonseca
}

Resumo

O presente trabalho pretende averiguar se as empresas que efetuam doações para partidos da coalizão do governo federal recebem maiores valores contratuais, antes e após as eleições. A partir de dados do Tribunal Superior Eleitoral (TSE) sobre doações de campanha de 2006 e de valores contratuais extraídos do Portal da Transparência do Governo Federal, foi estimado o efeito mínimo de doar para integrantes da coalizão sobre os valores contratuais. Embora os estimadores contenham viés de seleção, devido a variáveis omitidas e não observadas, a expectativa do viés é positiva devido à correlação também positiva entre tratamento e variável dependente, de um lado, e entre tratamento e variáveis omitidas, de outro. Isso significa que é possível estimar o efeito mínimo de doar para a coalizão sobre retornos contratuais. O efeito sobre retornos contratuais após as eleições é baixíssimo, mas os valores contratuais recebidos por empresas antes das eleições estão associados às doações de modo expressivo. Ademais, não é possível afirmar que doadores do partido do chefe do Executivo recebem maiores contratos em relação aos financiadores da oposição. Em suma, se existe algum pacto entre empresas e integrantes da coalizão, os acordos são estabelecidos e cumpridos antes das eleições.

PALAVRAS-CHAVE: financiamento eleitoral; eleições; coalizão; campanhas eleitorais, contratos governamentais.

Recebido em 14 de Setembro de 2015. Aceito em 6 de Novembro de 2015.

\section{Introdução}

$\mathrm{O}$ presente trabalho investiga se doadores de campanha são recompensados com valores provenientes de contratos públicos federais. Mais especificamente, pretende-se verificar duas indagações. Primeiro, se as empresas que doam para integrantes da coalizão governista recebem maiores recursos de contratos públicos federais. Segundo, se as empresas recebem maiores valores contratuais antes de realizarem as doações para a campanha, ou se recebem recompensas após a eleição.

Embora o emprego de modelos de regressão linear resulte em viés de seleção, a expectativa da correlação entre as variáveis omitidas e as variáveis de interesse, de um lado, e a dependente, de outro, é positiva. Isso significa que ainda é possível predizer o efeito mínimo das doações à coalizão governista sobre a recompensa proveniente dos contratos públicos. Como será discutido adiante, modelos probabilísticos sofisticados evitam o viés de seleção, mas mantém outras fontes de viés devido à própria natureza partidária do processo decisório e ao modo como os dados estão disponíveis. A regressão linear não é suficiente para evitar o viés dos estimadores, mas torna previsível a sua direção. 
Além disso, pretende-se testar se doadores do partido do presidente da república tem maiores vantagens quando comparado aos demais partidos, hipótese que não se confirma a partir da análise dos dados.

Na próxima seção, estudos pertinentes à proposta de trabalho serão discutidos, destacando os aspectos metodológicos do problema em questão. $\mathrm{Na}$ terceira seção serão apresentadas novas estratégias analíticas e o modelo a ser empregado, além dos supostos teóricos e probabilísticos que tornam a regressão linear viável, apesar das críticas realizadas pela literatura. Na quarta seção, os dados do banco serão relatados. Na quinta sessão, os principais resultados serão apresentados. Por fim os principais argumentos são retomados, contextualizando-os no debate sobre o assunto.

\section{A literatura sobre recompensa contratual dos doadores}

Parte da literatura sobre financiamento público de campanha buscou investigar se doadores são recompensados após a vitória de seus candidatos. Ainda não está claro se realmente os doadores são recompensados. Ansolabehere, Figueiredo e Snyder Jr. (2003), por exemplo, argumentaram que nos Estados Unidos a maior parte dos recursos é fornecida por pessoas físicas, e que seu retorno financeiro é muito baixo. Segundo os autores, o financiamento deveria ser visto principalmente como uma forma de participação política, e não como um investimento rentável.

No entanto, o impacto de doações sobre recompensas futuras ainda merece testes empíricos, principalmente quando são levadas em consideração as doações realizadas por empresas privadas em outros contextos institucionais, como no Brasil. Porém, antes é necessário compreender a natureza da recompensa que se pretende testar. Afinal, obter recompensas futuras por meio da representação política está dentro das regras do jogo democrático. Parte da literatura especializada, por exemplo, argumenta que doações geram impacto sobre o processo decisório de políticas públicas (Bronars \& Lott 1997; Santos et al., 2014; Welch 1982). Embora empresas possam ter mais poder de negociação em comparação com cidadãos individuais, distorcendo o princípio de um voto por indivíduo, ser representado por atores políticos na tomada de decisão ainda faz parte das regras do jogo.

Com a mesma preocupação, Jayachandran (2004) argumentou que quando a maioria de cadeiras no Senado - que anteriormente pertencia ao Partido Republicano - passou para o Partido Democrata, o valor das ações das empresas que contribuíram aos democratas aumentou no mercado sem que houvesse indícios de favorecimento ilícito. A princípio, a alteração do valor de ações a partir das perspectivas do mercado sobre a gestão política futura também não está em desencontro com as regras do jogo.

Entretanto, algumas recompensas violam as regras do jogo democrático e as regras da livre concorrência. Com esta preocupação implícita, alguns estudos testaram se doadores privados passam a receber vantagens econômicas futuras. Mancuso (2015) estabeleceu uma classificação indispensável para mapear os tipos de vantagem obtidos por doadores empresariais. A primeira vantagem se refere a empréstimos futuros fornecidos pelo Banco Nacional de Desenvolvimento Econômico e Social (BNDS) e conquistados por empresas que doaram no mandato anterior (Claessens, Feijen \& Laeven 2008; Lazzarini et al., 2011), ou ainda o financiamento obtido antes das eleições por grandes doadores do PT (Rocha 2011). A segunda diz respeito ao recebimento de benefícios tributários a partir de doações, segundo a evidência de que houve renúncias de receita por parte da União aos setores que contribuíram ao partido que conquistou o Poder 
Executivo (Gonçalves 2011). A terceira, explorada por Araújo (2008), envolve proteção comercial aos doadores, hipótese ainda não confirmada pelos testes.

A última vantagem - objeto de análise deste trabalho, inclusive - faz referência a outra fonte de recompensa presumidamente ilícita, a saber, vantagens sobre valores contratuais com o poder público (Arvate, Barbosa \& Fuzitani 2013; Oliveira \& Araújo 2013; Boas, Hidalgo \& Richardson 2014). Segundo os autores, empresas que doaram para deputados eleitos receberiam valores contratuais maiores no futuro quando comparadas às empresas que doaram para os candidatos perdedores.

De modo geral, os estudos mais recentes que tentam estimar o impacto das doações sobre recompensas contratuais se preocupam muito com os pressupostos dos modelos estatísticos e com a acurácia de seus estimadores. No entanto, negligenciaram outros pressupostos e problemas teóricos de natureza política, que prejudicam a validade do método empregado. Na próxima seção, os problemas analíticos da literatura recente serão revistos.

\section{Pressupostos políticos e estatísticos}

Os estudos mais recentes que pretenderam testar se empresas doadoras são recompensadas por valores contratuais futuros partem de três pressupostos políticos que merecem revisão (Arvate, Barbosa \& Fuzitani 2013; Oliveira \& Araújo 2013; Boas, Hidalgo \& Richardson 2014). Nesta seção, os pressupostos políticos e suas implicações serão analisados, para traçar uma nova estratégia analítica.

O primeiro suposto é o de que deputados eleitos, independentemente da filiação partidária, têm alguma influência individual sobre a distribuição valores contratuais. A possibilidade de propor emendas ao orçamento e conexões com o Executivo seriam mecanismos à disposição de deputados individuais eleitos para favorecer suas respectivas empresas doadoras. Mecanismos estes que os candidatos derrotados nas eleições não teriam (Arvate, Barbosa \& Fuzitani 2013; Oliveira \& Araújo 2013; Boas, Hidalgo \& Richardson 2014).

No entanto, o poder individual dos deputados sobre a distribuição de valores contratuais, independentemente da dinâmica partidária, não se justifica em termos teóricos. Em primeiro lugar, a aprovação de emendas individuais ao orçamento depende da dinâmica partidária e da decisão do Executivo. Do mesmo modo como recompensa seus aliados, o Executivo pode punir seus adversários. Afinal, porque o Executivo iria garantir privilégios às empresas que ajudaram seus adversários na disputa eleitoral?

Em segundo, o chefe do Executivo divide ministérios e estabelece acordos mais consistentes com os membros da coalisão. Por isso, seria mais sensato contar com a expectativa de que congressistas que pertencem a partidos da coalizão governista conquistem maior influência sobre a distribuição de valores contratuais.

Em terceiro, as doações de campanha não são alocadas apenas sobre candidatos individuais. Grande parte do volume de doações é dirigida a comitês e diretórios partidários, os quais redistribuem os recursos estrategicamente entre seus filiados. Em 2006, por exemplo, do total de valores doados da esfera federal, $42,9 \%$ diziam respeito a candidatos individuais, enquanto que o restante de $57,1 \%$ foi alocado diretamente em associações partidárias (comitês e diretórios). Portanto, desconsiderar as doações direcionadas às associações partidárias pode gerar um enorme viés.

Em quarto lugar, empresas que doam para candidatos não eleitos ajudam indiretamente seus respectivos partidos, uma vez que os votos dos perdedores 
são inseridos no cálculo do quociente eleitoral. Ou seja, mesmo que alguns atores financiados não fossem eleitos, talvez o partido recompense os doadores que ajudaram na busca pelo maior número de cadeiras.

Por isso, é necessário aplicar testes que levem em conta o partido do candidato financiado de modo adequado. Embora alguns estudos procurassem diferenciar os candidatos a partir da natureza de seu partido, de esquerda e de direita (Arvate, Barbosa \& Fuzitani 2013), ou ainda buscassem contrastar os candidatos do PT, da coalizão governista e da oposição (Boas, Hidalgo \& Richardson 2014), o tratamento ainda comparava os deputados individuais eleitos dos não eleitos. O presente trabalho, ao contrário, defende que a fonte de comparação deve residir em empresas que doam ou não à coalizão governista. O estudo parte da expectativa de que o poder dos congressistas membros da coalizão sobre a alocação de contratos é maior que o poder dos congressistas pertencentes à oposição.

$\mathrm{O}$ segundo suposto político diz respeito à incerteza eleitoral. Oliveira e Araújo (2013) aplicam o método de regressão descontínua apenas aos candidatos próximos à margem de vitória, para evitar o viés de seleção. Segundo os autores, para estimar o efeito do tratamento (ser eleito) é necessário que os doadores tenham incerteza quanto à vitória de seus candidatos financiados.

A preocupação em garantir incerteza ao tratamento não é supérflua. Entretanto, a distância entre candidatos individuais vencedores e perdedores, medida por número de votos, é utilizada como o indicador de incerteza eleitoral, o que impede que a dinâmica partidária seja inserida na análise. Ou seja, apesar de obter estimadores acurados, os dados envolvem apenas candidatos que recebem doações individuais diretamente, excluindo o valor recebido por doações endereçadas a comitês e diretórios partidários que, posteriormente, são redistribuídas entre os próprios candidatos.

O presente trabalho não garante a ausência de viés de seleção. No entanto, a direção do viés permite inferir o efeito mínimo que o tratamento exerce sobre a variável dependente. A nova estratégia analítica proposta na próxima seção evita que sejam negligenciadas as doações dirigidas às organizações partidárias, que são livremente realocadas.

O terceiro suposto político se refere ao momento em que a recompensa financeira é conferida às empresas doadoras. Os estudos recentes partem da expectativa de que os financiadores esperam ser recompensados no futuro, após seus candidatos serem eleitos. No entanto, por que uma empresa confiaria no comprometimento dos atores políticos em recompensá-la no futuro? Que instrumentos as empresas teriam para garantir a recompensa em forma de valores contratuais? Seriam estas empresas tomadoras de risco?

O presente trabalho, ao contrário, parte da expectativa de que acordos são estabelecidos e cumpridos antes do novo mandato. Empresas recebem valores contratuais maiores que os concorrentes porque pretendem doar para a coalizão durante as próximas eleições. Elas, espera-se, não admitem correr grandes riscos e, por isso, se comprometem a creditar doações porque conquistaram contratos valiosos antes da corrida eleitoral. Isso não significa que devemos desvalidar a hipótese contemplada pela literatura, segundo a qual as empresas que doam para ganhadores receberiam vantagens no futuro. Afinal, uma empresa que faz doações antes do novo mandato pode estabelecer laços de confiança com atores políticos em longo prazo. Entretanto é razoável supor que estes laços de confiança são mais incertos do que parcerias que não dependam de um grande espaço de tempo. A Figura 1 ilustra o argumento.

Após as eleições, governos poderiam quebrar acordos, favorecendo os concorrentes dos doadores e, consequentemente, evitariam sofrer com a 
Figura 1 - Representação dos modelos explicativos acerca das expectativas sobre o período de estabelecimento e cumprimento de acordos

Modelo pós-eleitoral (Hipótese da literatura)

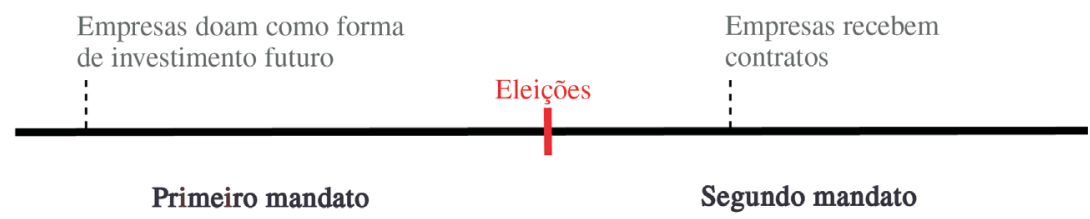

Modelo pré-eleitoral (Nova hipótese)

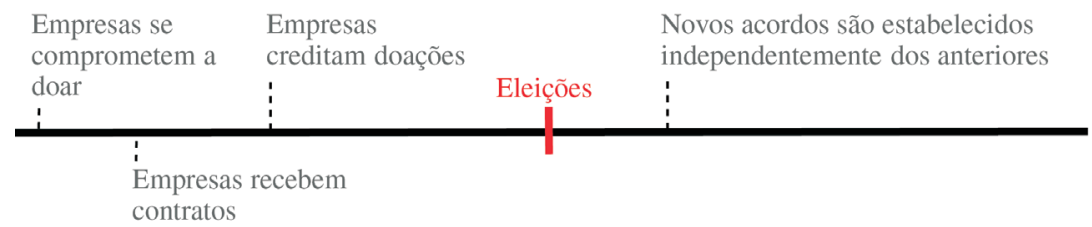

Primeiro mandato Segundo mandato

Fonte: Elaboração própria.

carência de fornecedores de produtos e serviços (modelo pós-eleitoral). Por outro lado, empresas seriam incentivadas a não quebrar contratos por iniciativa própria como forma de punição aos governos que descumprissem acordos. Isso porque organizações que pretendessem sancionar governos receberiam o mesmo ônus de sua represaria: não poderiam exercer atividades contratuais. Este quadro leva os doadores a não confiarem em recompensas futuras.

Governos, ao contrário, correriam menor risco se os doadores se comprometessem a creditar doações antes das eleições (modelo pré-eleitoral). Afinal, empresas poderiam ser banidas de qualquer participação contratual no futuro, caso forças políticas que não recebessem sua parte do acordo antes das eleições voltassem a alcançar o poder no próximo mandato. Ademais, governos já eleitos só concorrem nas próximas eleições, enquanto que a concorrência no mundo empresarial ocorre durante todo o mandato.

Poucos estudos contribuíram para gerar a suspeita de que vantagens são distribuídas antes de novas eleições. Segundo Rocha (2011), quanto maior o dispêndio do BNDS recebido por empresas entre 2008 e 2010, maiores foram os valores doados ao Partido dos Trabalhadores em 2010. Ao coletar reportagens que associam benefícios futuros à contribuição de campanha, Mezzarana (2009) também identificou casos em que as doações são creditadas somente após o recebimento de vantagens. Resta saber se esta suspeita se confirma a partir de modelos estatísticos.

Os novos testes propostos neste trabalho não são suficientes para desvalidar completamente a hipótese segundo a qual a maior parte dos ganhos contratuais ocorre depois das eleições. Entretanto, oferecem uma importante contribuição ao averiguar com igual importância a hipótese concorrente, segundo a qual doadores estabelecem e cumprem acordos antes das eleições.

\section{Nova estratégia analítica empregada}

Nesta seção, duas estratégias novas serão empregadas. A primeira consiste em averiguar a direção do viés do efeito do tratamento, a fim de verificar se é possível estimar seu efeito mínimo. A segunda pretende empregar como variável dependente os valores contratuais recebidos antes das eleições, para verifi- 
${ }^{1}$ Mais especificamente, Oliveira e Araújo (2013) utilizam como tratamento o cumprimento de pelo menos um ano exercido por deputados federais.
${ }^{2}$ Segundo Wooldridge (2002, cap. 3), se a variável não observável se correlaciona positivamente com ambas, a variável de interesse independente e a variável dependente, o viés é positivo. car se o ganho dos doadores ocorre em função de supostos acordos estabelecidos com a coalizão governista antes das eleições.

Os estudos recentes que almejaram verificar se empresas doadoras recebem recompensas contratuais futuras utilizam como tratamento o fato de o candidato financiado conquistar uma cadeira como deputado federal (Arvate, Barbosa \& Fuzitani 2013; Oliveira \& Araújo 2013) ${ }^{1}$. A saída para evitar o viés de seleção seria aplicar o método de regressão descontínua. No entanto, tal procedimento teria um custo: depender de outros supostos teóricos de difícil sustentação discutidos na seção anterior. Esse problema poderia ser resolvido com a regressão linear, caso fosse possível lidar com o viés de seleção de outro modo, a saber, verificar se sua direção permite inferir estimadores mínimos para o efeito do tratamento. Como será argumentado adiante, as fontes de viés geram um viés positivo, o que permite estimar o efeito mínimo do tratamento.

As equações a seguir representam, respectivamente, o modelo real esperado e o modelo estimado sem as variáveis omitidas.

$$
\begin{aligned}
& \text { Valor contratual }_{i}=\rho D_{i}+X_{i}^{\prime} \beta+O_{i}^{\prime} \gamma+e_{i} \\
& \text { Valor contratual }_{i}=\hat{\rho} D_{i}+X_{i}^{\prime} \hat{\beta}+u_{i}
\end{aligned}
$$

onde $D_{i}$ é o tratamento, $\rho$ o efeito do tratamento, $X_{i}^{\prime}$ o conjunto de variáveis de controle, $O_{i}^{\prime}$ o conjunto de variáveis omitidas, e $u_{i}$ e $e_{i}$ os erros. Se as variáveis omitidas não forem independentes do tratamento e da variável independente, o estimador do efeito do tratamento, $\rho$ será enviesado $\left[E\left(u_{i} \mid D_{i}\right) \neq 0\right]$. Se a expectativa dos estimadores das variáveis omitidas for positiva $[\gamma>0]-$ ou seja, se a correlação entre a variável dependente e as variáveis omitidas for positiva -, e se a correlação entre o tratamento e variáveis omitidas também for positiva $\left[\operatorname{Corr}\left(D_{i}, O_{i}^{\prime}\right)>0\right]$, o viés esperado do efeito do tratamento, $\rho$, é positivo ${ }^{2}[\rho>\hat{\rho}]$.

Diferentemente da literatura recente, neste trabalho o tratamento $D_{i}$ diz respeito a doações direcionadas aos partidos da coalizão governista. Mesmo com a alteração, as variáveis omitidas destacadas pela literatura também são responsáveis por gerar a expectativa de um viés positivo sobre o efeito estimado, $\hat{\rho}$.

O primeiro tipo de variáveis omitidas destacado pela literatura está ligado às características de gestão das empresas doadoras. De um lado, os estudos supõem que empresas mais eficientes e com corpo diretivo mais agressivo teriam maior capacidade financeira para realizar doações e uma maior propensão em estabelecer relações políticas com atores capazes de prover seus interesses (Oliveira \& Araújo 2013) - neste trabalho, aqueles que pertencem à coalizão. É plausível supor também que estas empresas teriam mais chances de conseguir valores contratuais maiores devido à sua própria eficiência e agressividade. Em outras palavras, a eficiência e a agressividade das empresas estariam positivamente correlacionadas com o tratamento e com o resultado.

A literatura sobre retornos contratuais não menciona outras variáveis que estão vinculadas à própria organização das empresas ou ao seu papel assumido no mercado. Sem dúvida, a falta de dados é o maior empecilho para inseri-las nos testes. Os estudos que inseriram de modo conjunto doações de campanha e características do mundo empresarial não empregaram como variável dependente o valor contratual. E mais importante, não é possível adaptar o modo como seus dados foram organizados com o banco deste trabalho. Araújo (2008) inseriu na analise a competitividade a partir da proxy "quantidade de empregados" e a balança comercial do setor, mas as unidades de observação (linhas do banco) se referem ao setor econômico, e não a empresas individuais. Para analisar o efeito de doações de campanha sobre o desempenho das empresas, 
Mello e Marcon (2005) empregaram variáveis ligadas a características internas das empresas e ao setor econômico de sua atuação, mas, por falta de dados, restringiram-se a analisar empresas públicas, excluindo grande parte dos doadores.

O presente trabalho, ao contrário, almejou abordar todos os doadores empresariais. Estudos futuros podem e devem adotar novas estratégias, mas em um primeiro momento seria útil aplicar modelos que abarcassem todos os casos. De qualquer forma, também é plausível esperar que variáveis como o porte das empresas, o nível de organização em seu segmento e capacidade de obter financiamento também estejam positivamente correlacionados com ambos, obtenção de contratos mais rentáveis (variável dependente) e preferência em doar para a coalizão (tratamento). Ou ainda, é razoável supor que algumas destas variáveis estejam associadas apenas à variável dependente (valores contratuais), sem qualquer vínculo à preferência de contribuir à coalizão, o que não enviesaria o efeito do tratamento em caso de ausência. Os testes empreendidos a seguir admitem a validade deste suposto.

O segundo tipo de viés ressaltado pela literatura é derivado da falta de incerteza das empresas doadoras quanto o sucesso eleitoral dos candidatos (Oliveira \& Araújo 2013). O presente trabalho considera que quanto maior a probabilidade de candidatos vitoriosos virem a pertencer à coalizão, maiores seriam os valores doados pelas empresas, uma vez que elas aumentariam sua expectativa de obter maiores retornos contratuais caso seus candidatos fossem eleitos. Por outro lado, quanto maior a probabilidade de sucesso de os candidatos pertencerem à coalizão, maior a capacidade destes mesmos atores em prover retornos contratuais aos seus financiadores. Portanto, a variável omitida (falta incerteza eleitoral) estaria positivamente associada ao tratamento (doar à coalizão) e à variável dependente (valor contratual).

As equações a seguir representam, respectivamente, o novo modelo real esperado e o modelo estimado sem as variáveis omitidas.

Valor contratual $_{i}=\rho D_{i}+\gamma_{1}$ efic $_{i}+\gamma_{2}$ agress $_{i}+\gamma_{3} \operatorname{Pr}\left(\in\right.$ coalizão $_{i}+X_{i}^{\prime} \beta+e_{i}$

Valor contratual $_{i}=\hat{\rho} D_{i}+X_{i}^{\prime} \hat{\beta}+u_{i}$

Ao omitir as variáveis de eficiência, agressividade e a probabilidade de pertencer à coalizão, a expectativa do viés do efeito estimado do tratamento $\hat{\rho}$ continua positiva $(\rho>\hat{\rho})$. Isso significa que, embora o efeito estimado do tratamento, $\hat{\rho}$, possa ser menor do que o efeito real, $\rho$, ainda é analiticamente útil, uma vez que representa o retorno contratual mínimo das empresas que doam para integrantes da coalizão governista. Desse modo, nos livramos do suposto de que candidatos individuais eleitos teriam poder sobre a alocação de contratos independentemente de partidos e alianças políticas.

Para aplicar a nova estratégia analítica, as unidades de observação serão adaptadas. Deixam de ser o total de recursos recebidos pelo candidato, e são substituídas pelo valor total doado por uma empresa a um partido independentemente se os recursos foram endereçados às associações partidárias ou aos candidatos individuais. Assim, poderão ser acrescentadas à análise as doações endereçadas às associações partidárias, que em 2006 representaram 57,1\% do total dos recursos empresariais.

Como afirmado anteriormente, a partir dos testes será possível comparar, alternadamente, duas variáveis dependentes: o valor contratual obtido antes e após as eleições (Figura 1). 
Vale ressaltar que a direção causal entre tratamento (doar para a coalizão) e variável dependente (valor contratual) não deve ser alterada quando o teste está vinculado ao mandato antes da alternância de mandato. Como ilustra a Figura 1 da seção anterior, a presente hipótese supõe que as empresas se comprometem a doar antes de receberem valores contratuais, mas só podemos observar as contribuições prometidas momentos antes das eleições.

Na próxima seção, a elaboração do banco de dados e suas variáveis serão relatadas.

\section{Os dados}

\footnotetext{
${ }^{3}$ Disponível em: http://www.tse.jus.br/eleicoes/ estatisticas/repositorio-de-dad os-eleitorais. Acesso em 13 fev. 2017.
}

Os dados de doações de campanha provêm do Repositório de Dados Eleitorais do Tribunal Superior Eleitoral ${ }^{3}$. Foram coletados os dados de doações realizadas por empresas privadas a candidatos individuais, para os três cargos de presidente, senador e deputado federal, e a associações partidárias federais (comitês e diretórios) na disputa eleitoral de 2006.

Os dados referentes a valores contratuais federais recebidos por empresas privadas foram coletados no Portal da Transparência do Governo Federal por web scraping, para os anos de 2004 a 2006 e 2008 a 2010. Como sugerido por Oliveira e Araújo (2013), os valores contratuais recebidos pelas empresas durante o primeiro ano de cada mandato devem ser excluídos do banco, uma vez que o Plano Plurianual entra em vigor sempre a partir do segundo ano de cada mandato. O CNPJ das empresas que receberam contratos foi cruzado com o CNPJ de doadores mencionados no banco de dados do Tribunal Superior Eleitoral (TSE). A partir do CNPJ da empresa, os valores contratuais recebidos por um mesmo partido provenientes de uma mesma empresa foram somados para constituir as unidades de observação.

Os dados ligados a coalizão governista foram acrescentados a partir do banco de dados do Cebrap. Foram considerados apenas os integrantes da coalizão para o primeiro e segundo mandato do governo Lula. Embora fossem excluídos os valores contratuais do primeiro ano de cada mandato devido aos tramites da execução orçamentária, foram considerados todos os integrantes que participaram da coalizão durante todo o mandato, mesmo que envolvessem o primeiro ano de governo, uma vez que os atores políticos participam da elaboração dos Planos Plurianuais desde o início do mandato. Uma dummy foi criada para representar empresas que doaram para partidos que participaram da coalizão, ou seja, que participaram durante um ano pelo menos (coalizaol).

Embora a unidade de observação seja o valor total doado por uma empresa a um partido, foi identificado: (1) se, do montante desse valor, parte era destinada a candidatos individuais ou a comitês e diretórios; (2) se parte era dirigida à disputa para o cargo de presidente, senador e deputado. A partir destes dados foram criadas dummies. As dummies de doações destinadas a partidos ou a candidatos individuais são excludentes, enquanto as dummies de disputa de cargos específicos não são excludentes. Ou seja, uma mesma empresa pode ter doado para deputados e senadores - portanto, se uma empresa fez doações a deputados isso não significa que não tenha financiado senadores.

Outras dummies complementares foram criadas. Primeiro, para identificar se a empresa doou para partidos que integravam ambos, coalizão governista e oposição (doadob), e se doadores contribuíram apenas para a coalizão (coalizao2). Segundo, para identificar se o doador contribuiu para o partido do presidente (do_part_exec) e para o restante da coalizão (coalizao3). Na próxima seção, os principais resultados serão analisados. 


\section{Resultados}

O primeiro conjunto de modelos (Tabela 1) testa se empresas que doam para partidos da coalizão governista (coalizao1) obtêm maior retorno contratual em relação aos doadores exclusivos da oposição. Também foram empregados três tipos de controle. O primeiro se refere ao valor doado (valor_doacao). $\mathrm{O}$ segundo diz respeito à doação endereçada para comitês e diretórios partidários (doapart), para o partido e candidato individual (doaindpart), e apenas para o candidato, sendo esta última variável omitida para evitar multicolinearidade. O terceiro envolve doações para presidente (doa_pres), senador (doa_sen) e

Tabela 1 - Efeito de doar para a coalizão e do valor doado sobre valores contratuais recebidos

\begin{tabular}{|c|c|c|c|c|}
\hline \multirow[b]{2}{*}{ Variável } & \multicolumn{2}{|c|}{ Valor contratual obtido antes das eleições } & \multicolumn{2}{|c|}{ Valor contratual obtido após as eleições } \\
\hline & Modelo 1 & Modelo 2 & Modelo 3 & Modelo 4 \\
\hline \multirow[t]{3}{*}{ coalizao1 } & 801.84 & 657.47 & 1.15 & 0.90 \\
\hline & 273.38 & 283.14 & 0.50 & 0.52 \\
\hline & 0.003 & 0.020 & 0.020 & 0.080 \\
\hline \multirow[t]{3}{*}{ valor_doacao } & 10.54 & 7.47 & 0.00 & -0.01 \\
\hline & 1.07 & 1.90 & 0.00 & 0.00 \\
\hline & 0.000 & 0.000 & 0.981 & 0.127 \\
\hline \multirow[t]{3}{*}{ doapart ${ }^{\mathrm{I}}$} & 1083.58 & 1087.83 & -5.10 & -5.09 \\
\hline & 404.45 & 404.43 & 0.74 & 0.74 \\
\hline & 0.007 & 0.007 & 0.000 & 0.000 \\
\hline \multirow[t]{3}{*}{ doaindpart II } & 8781.91 & 8846.89 & 9.35 & 9.46 \\
\hline & 952.30 & 952.82 & 1.73 & 1.73 \\
\hline & 0.000 & 0.000 & 0.000 & 0.000 \\
\hline \multirow[t]{3}{*}{ doa_pres III } & -992.65 & -928.78 & -2.22 & -2.10 \\
\hline & 682.15 & 682.89 & 1.24 & 1.24 \\
\hline & 0.146 & 0.174 & 0.074 & 0.091 \\
\hline \multirow[t]{3}{*}{ doa_sen ${ }^{\mathrm{IV}}$} & -13.43 & 8.73 & 3.55 & 3.59 \\
\hline & 467.24 & 467.35 & 0.85 & 0.85 \\
\hline & 0.977 & 0.985 & 0.000 & 0.000 \\
\hline \multirow[t]{3}{*}{ coal1_doa $^{\mathrm{v}}$} & & 4.29 & & 0.01 \\
\hline & & 2.19 & & 0.00 \\
\hline & & 0.050 & & 0.062 \\
\hline \multirow[t]{3}{*}{ Constante } & 756.57 & 850.08 & 17.27 & 17.43 \\
\hline & 229.83 & 234.73 & 0.42 & 0.43 \\
\hline & 0.001 & 0.000 & 0.000 & 0.000 \\
\hline $\mathrm{N}$ & 22419 & 22419 & 22419 & 22419 \\
\hline r2_a & 0.01 & 0.01 & 0.01 & 0.01 \\
\hline
\end{tabular}

Fonte: Elaboração própria.

Observação: Os valores para cada variável se referem, respectivamente, ao estimador, erro padrão e índice de significância; cada unidade de medida dos estimadores equivale a $\mathrm{R} \$ 1.000$.

IDoação endereçada para comitês e diretórios partidários.

IIDoação para o partido e candidato individual.

IIIDoações para presidente.

${ }^{\mathrm{IV}}$ Doações para senador.

${ }^{\vee}$ Variável de Interação. 
deputado federal, esta última também omitida. A variável dependente dos modelos 1 e 2 se refere ao retorno contratual antes das eleições, enquanto que a variável dependente dos modelos 3 e 4 diz respeito a recompensas futuras. Os modelos 2 e 4 apresentam uma variável de interação entre o tratamento coalizãol e o valor_doacao. Os valores doados e contratuais obtidos foram divididos por mil para tornar os estimadores mais claros (Tabela 1).

Exceto o modelo 4, doar para membros da coalizão aumenta o retorno de valores contratuais significativamente. Mas o que chama a atenção é que os modelos com retornos contratuais antes das eleições (modelos 1 e 2) apresentam estimadores bem maiores que os modelos que estimam impacto sobre recompensas futuras. Segundo o modelo 1, por exemplo, independentemente do valor doado, empresas que doam para integrantes da coalizão receberam em média pelo menos $\mathrm{R} \$ 819$ mil a mais que os doadores de membros que pertenceram à oposição. Vale lembrar que o efeito real das variáveis independentes pode ser ainda maior que o efeito estimado, devido ao viés positivo gerado pela omissão de variáveis não observadas discutidas anteriormente. Por outro lado, os estimadores mínimos dos modelos 3 e 4 são residuais.

O Gráfico 1 ajuda a visualizar a diferença mínima entre doar para a coalizão entes e após as eleições, estimada a partir dos modelos 1 e 3. Apesar do grande intervalo de confiança, temos clareza que a diferença contratual recebida antes das eleições é elevada. Após as eleições, ao contrário, o valor mínimo estimado é muito baixo.

A variável interativa (coall_doa) que mede o efeito do valor doado sobre o efeito do tratamento (coalizaol) é significativa apenas para o período pré-eleitoral, como indica o modelo 2. O Gráfico 2 ilustra com maior clareza como o efeito de ter doado para a coalizão se altera conforme o valor doado pelas empresas aumenta. A diferença contratual média entre empresas que doaram para a coalizão e doadores da oposição chega a ultrapassar 40 milhões de acordo com o aumento da doação. O intervalo de confiança é maior para doações mais elevadas, porque o número dos grandes doadores é bem menor que o dos pequenos doadores.

Ainda segundo a Tabela 1, em relação às empresas que doaram apenas para candidatos individuais, aqueles que doaram exclusivamente para os partidos

Gráfico 1 - Valor contratual recebido por doadores da coalizão antes e após às eleições

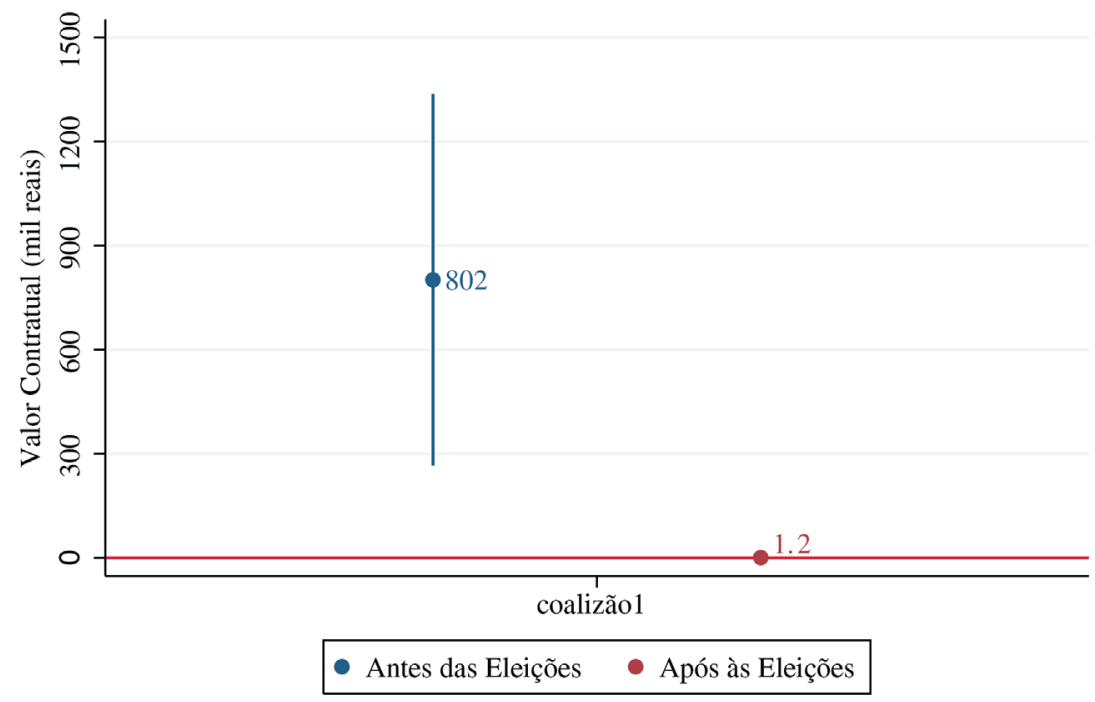

Fonte: Elaboração própria. 
Gráfico 2 - Efeito de doar para a coalizão sobre valores contratuais recebidos antes das eleições em função do valor doado

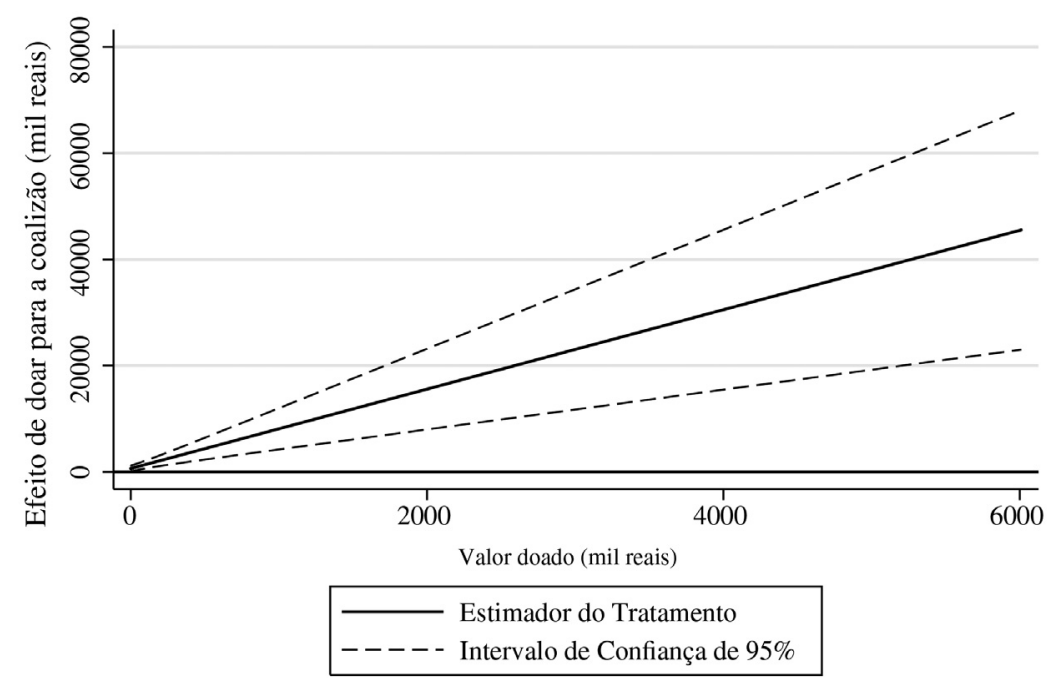

Fonte: Elaboração própria.

ganham uma diferença contratual média de $\mathrm{R}$ \$1,08 milhão antes das eleições, enquanto que as organizações que doaram de ambas as formas obtiveram em média R \$ 8,78 milhões (modelo 1). No entanto, estes estimadores devem ser examinados com cautela, uma vez que sua validade também depende dos supostos discutidos na seção anterior. Em relação ao período pós-eleitoral (modelo 3), os estimadores não ultrapassam R $\$ 10$ mil, embora significativos. O Gráfico 3 compara as formas de doação para os dois períodos, reforçando a hipótese de que acordos nascem e acabam antes das próximas eleições.

Gráfico 3 - Retorno contratual para doadores de partidos e de ambos, partidos e candidatos individuais

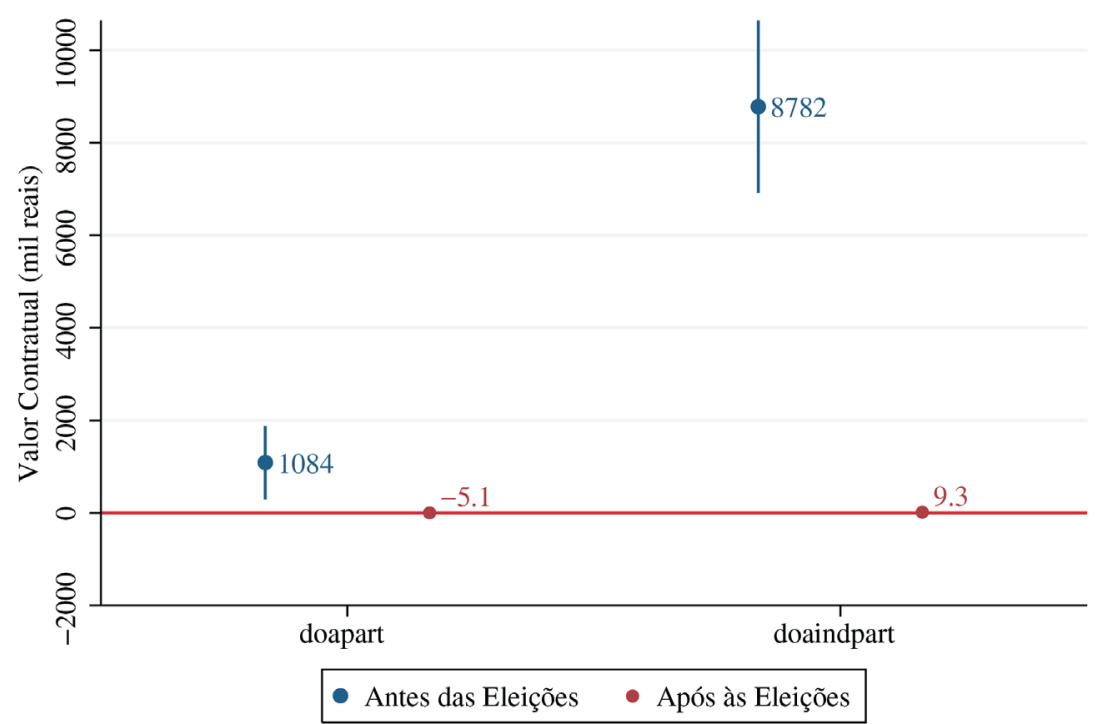

Fonte: Elaboração própria.

Doação endereçada para comitês e diretórios partidários (doapart)

Doação para o partido e candidato individual (doaindpart) 
No segundo conjunto de modelos, apresentado na Tabela 2, verifica-se que empresas que efetuam doações para ambos os grupos, coalizão governista e oposição, são mais beneficiadas com valores contratuais. Os modelos 1 e 2 se referem ao valor contratual obtido durante o primeiro mandato (antes das eleições), enquanto os modelos 3 e 4 estimam o impacto sobre valores contratuais após as eleições. Diferentemente dos modelos anteriores da Tabela 1, os novos testes empregam as variáveis doadob e coalizao2, que representam,

Tabela 2 - Efeito de doar apenas para ambos, coalizão e oposição, e exclusivamente para coalizão

\begin{tabular}{|c|c|c|c|c|}
\hline \multirow[b]{2}{*}{ Variável } & \multicolumn{2}{|c|}{ Valor contratual obtido antes das eleições } & \multicolumn{2}{|c|}{ Valor contratual obtido após as eleições } \\
\hline & Modelo 1 & Modelo 2 & Modelo 3 & Modelo 4 \\
\hline \multirow[t]{3}{*}{ Doadob $^{\text {I }}$} & 4062.61 & 3995.01 & 9.04 & 9.80 \\
\hline & 433.90 & 454.95 & 0.79 & 0.83 \\
\hline & 0.000 & 0.000 & 0.000 & 0.000 \\
\hline \multirow[t]{3}{*}{ coalizao2 } & 736.20 & 737.47 & 1.48 & 1.46 \\
\hline & 295.71 & 295.73 & 0.54 & 0.54 \\
\hline & 0.013 & 0.013 & 0.006 & 0.006 \\
\hline \multirow[t]{3}{*}{ valor_doacao II } & 9.73 & 9.41 & -0.00 & 0.00 \\
\hline & 1.08 & 1.26 & 0.00 & 0.00 \\
\hline & 0.000 & 0.000 & 0.358 & 0.407 \\
\hline \multirow[t]{3}{*}{ doapart III } & 712.66 & 717.24 & -5.94 & -5.99 \\
\hline & 405.67 & 405.78 & 0.74 & 0.74 \\
\hline & 0.079 & 0.077 & 0.000 & 0.000 \\
\hline \multirow[t]{3}{*}{ doaindpart ${ }^{\text {IV }}$} & 8072.54 & 8066.31 & 7.73 & 7.80 \\
\hline & 953.68 & 953.78 & 1.73 & 1.73 \\
\hline & 0.000 & 0.000 & 0.000 & 0.000 \\
\hline \multirow[t]{3}{*}{ doa_presidente ${ }^{\mathrm{v}}$} & -980.29 & -991.65 & -2.16 & -2.03 \\
\hline & 680.92 & 681.32 & 1.24 & 1.24 \\
\hline & 0.150 & 0.146 & 0.082 & 0.102 \\
\hline \multirow[t]{3}{*}{ doa_senador ${ }^{\mathrm{VI}}$} & -80.50 & -79.38 & 3.41 & 3.40 \\
\hline & 466.43 & 466.44 & 0.85 & 0.85 \\
\hline & 0.863 & 0.865 & 0.000 & 0.000 \\
\hline doadob_doa VII & & 1.08 & & -0.01 \\
\hline \multirow[t]{3}{*}{ Constante } & 405.27 & 413.38 & 16.18 & 16.09 \\
\hline & 245.90 & 246.45 & 0.45 & 0.45 \\
\hline & 0.099 & 0.093 & 0.000 & 0.000 \\
\hline N & 22419 & 22419 & 22419 & 22419 \\
\hline r2_a & 0.02 & 0.02 & 0.01 & 0.01 \\
\hline
\end{tabular}

Fonte: Elaboração própria.

Observação: Os valores para cada variável se referem, respectivamente, ao estimador, erro padrão e índice de significância; cada unidade de medida dos estimadores equivale a $\mathrm{R} \$ 1.000$.

IA empresa doou para partidos que integravam ambos, coalizão governista e oposição.

IIDoadores que contribuíram apenas para a coalizão.

IIIDoação endereçada para comitês e diretórios partidários.

${ }^{\text {IV }}$ Doação para o partido e candidato individual.

${ }^{\vee}$ Doações para presidente.

${ }^{\mathrm{VI} D o a c ̧ o ̃ e s ~ p a r a ~ s e n a d o r . ~}$

VIIVariável de interação. 
respectivamente, doadores de ambos os grupos e doadores exclusivos da coalizão. Os modelos 2 e 4 possuem a variável de interação doadob_doa, que testa se o valor doado altera o efeito do tratamento doadob.

As variáveis doadob e coalizao2 são significativas em todos os modelos, mas o que chama a atenção é a diferença de magnitude entre o efeito estimado antes (modelos 1 e 2) e após as eleições (modelos 3 e 4). A diferença contratual média entre doadores de ambos os lados e doadores da oposição equivale a pelo menos R \$,1 milhões (modelo 1), enquanto que após as eleições a diferença contratual mínima cai para R \$ 9 mil (modelo 3). Ainda em relação aos doadores da oposição, empresas que doam apenas para a coalizão (coalizao2) recebem em média $\mathrm{R}$ \$ 736 mil a mais antes das eleições, enquanto após as eleições o valor cai para $\mathrm{R} \$ 1,5$ mil. A variável de interação doadob_doa, por sua vez, não é significativa no modelo pré-eleitoral, e sua magnitude é muito baixa quando o período pós-eleitoral é avaliado.

O Gráfico 4 facilita a comparação entre os estimadores. É possível notar com maior clareza que antes das novas eleições empresas que doam para ambos os lados obtém um valor contratual muito maior que os doadores exclusivos da coalizão. Após as eleições os estimadores são muito mais baixos.

Dado que o partido que conquistou a Presidência da República possui instrumentos institucionais mais vantajosos para implementar sua agenda, é possível que as empresas prefiram financiá-lo em detrimento do restante da coalizão. Os modelos da Tabela 3 comparam os doadores do partido do Executivo (part_exec) e os demais membros da coalizão (coalizao3) com aqueles que contribuíram apenas para a oposição. Os modelos 2 e 4 inserem as variáveis de interação exec_doa e coal3_doa para verificar se o valor doado altera o valor dos estimadores part_exec e coalizao3, respectivamente.

Não é possível afirmar que doadores do partido do Executivo recebem valores contratuais mais altos que os da oposição antes das eleições, devido à significância insatisfatória (modelos 1 e 2). Após as eleições, por sua vez, a diferença de valores é pouco expressiva, por não ultrapassar $\mathrm{R} \$ 2$ mil. Por outro lado, os doadores do restante da coalizão chegam a ganhar R \$1,08 milhão a mais que os da oposição antes das eleições (modelo1). A mesma associação não

Gráfico 4 - Valor contratual recebido por doadores de ambos, coalização e oposição, e de doadores exclusivos da coalizão

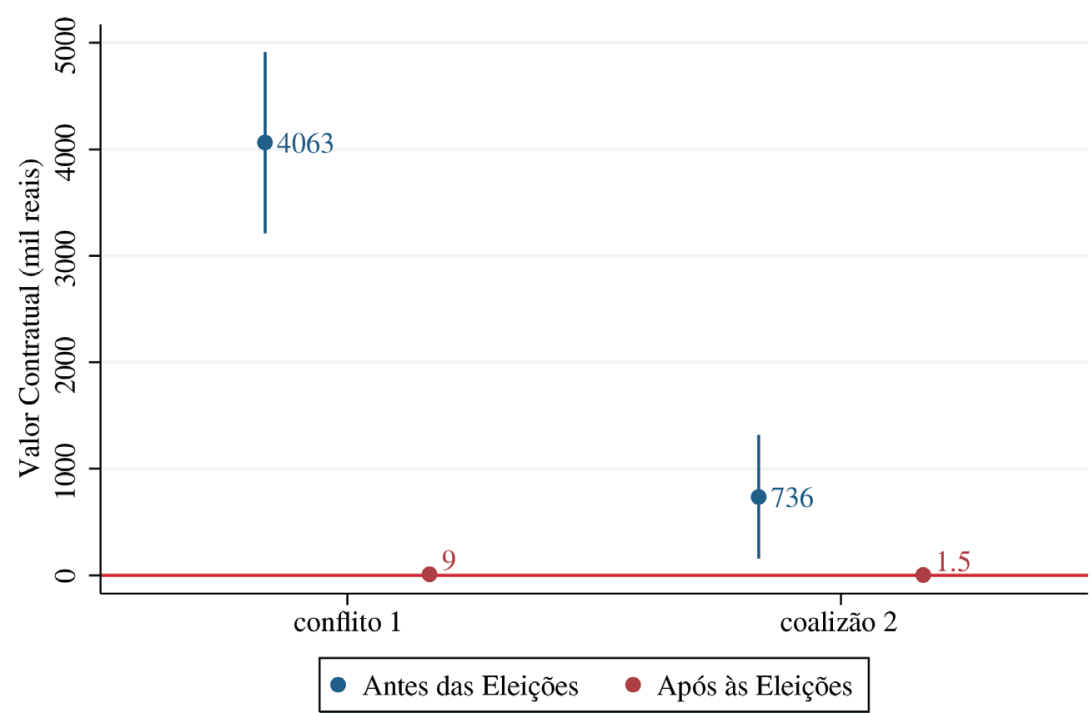

Fonte: Elaboração própria. 
Tabela 3 - Efeito de doar para o partido do presidente ou para o restante da coalizão sobre valores contratuais recebidos

\begin{tabular}{|c|c|c|c|c|}
\hline \multirow[b]{2}{*}{ Variável } & \multicolumn{2}{|c|}{ Valor contratual obtido antes das eleições } & \multicolumn{2}{|c|}{ Valor contratual obtido após as eleições } \\
\hline & Modelo 1 & Modelo 2 & Modelo 3 & Modelo 4 \\
\hline \multirow[t]{3}{*}{ part_exec ${ }^{I}$} & 67.36 & 237.92 & 1.82 & 1.61 \\
\hline & 394.66 & 405.63 & 0.72 & 0.74 \\
\hline & 0.864 & 0.558 & 0.011 & 0.029 \\
\hline \multirow[t]{3}{*}{ coalizao3 } & 1076.69 & 437.11 & 0.90 & 0.57 \\
\hline & 293.37 & 304.31 & 0.53 & 0.56 \\
\hline & 0.000 & 0.151 & 0.091 & 0.307 \\
\hline \multirow[t]{3}{*}{ valor_doacao } & 10.59 & 7.47 & -0.00 & -0.01 \\
\hline & 1.08 & 1.90 & 0.00 & 0.00 \\
\hline & 0.000 & 0.000 & 1.000 & 0.143 \\
\hline \multirow[t]{3}{*}{ doapart II } & 1016.20 & 437.08 & -5.04 & -5.17 \\
\hline & 405.24 & 408.32 & 0.74 & 0.75 \\
\hline & 0.012 & 0.284 & 0.000 & 0.000 \\
\hline \multirow[t]{3}{*}{ doaindpart ${ }^{\text {III }}$} & 8709.75 & 7971.06 & 9.41 & 9.33 \\
\hline & 952.59 & 954.20 & 1.73 & 1.74 \\
\hline & 0.000 & 0.000 & 0.000 & 0.000 \\
\hline \multirow[t]{3}{*}{ doa_presidente IV } & -526.37 & 516.27 & -2.64 & -2.28 \\
\hline & 705.61 & 711.50 & 1.28 & 1.30 \\
\hline & 0.456 & 0.468 & 0.040 & 0.080 \\
\hline \multirow[t]{3}{*}{ doa_senador ${ }^{\mathrm{V}}$} & 18.23 & -20.88 & 3.53 & 3.55 \\
\hline & 467.34 & 466.45 & 0.85 & 0.85 \\
\hline & 0.969 & 0.964 & 0.000 & 0.000 \\
\hline \multirow[t]{3}{*}{ exec_doa VI } & & -3.46 & & 0.01 \\
\hline & & 2.33 & & 0.00 \\
\hline & & 0.138 & & 0.216 \\
\hline \multirow[t]{3}{*}{ coal3_doa VI } & & 23.01 & & 0.01 \\
\hline & & 2.84 & & 0.01 \\
\hline & & 0.000 & & 0.027 \\
\hline \multirow[t]{3}{*}{ Constante } & 737.85 & 893.31 & 17.29 & 17.45 \\
\hline & 229.91 & 234.27 & 0.42 & 0.43 \\
\hline & 0.001 & 0.000 & 0.000 & 0.000 \\
\hline $\mathrm{N}$ & 22419 & 22419 & 22419 & 22419 \\
\hline r2_a & 0.01 & 0.02 & 0.01 & 0.01 \\
\hline
\end{tabular}

Fonte: Elaboração própria.

Observação: Os valores para cada variável se referem, respectivamente, ao estimador, erro padrão e índice de significância; cada unidade de medida dos estimadores equivale a $\mathrm{R} \$ 1.000$.

IDoadores do partido do Executivo.

IIDoação endereçada para comitês e diretórios partidários.

IIIDoação para o partido e candidato individual.

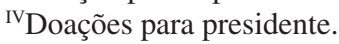

${ }^{\mathrm{V}}$ Doações para senador.

${ }^{\mathrm{VI} V a r i a ́ v e i s ~ d e ~ i n t e r a c ̧ a ̃ o . ~}$ 
se confirma no período pós-eleitoral, além dos baixos estimadores (modelo 3). O Gráfico 5 ilustra com clareza a diferença entre os estimadores.

Segundo os modelos 2 e 4 , não é possível afirmar que o valor doado gera efeito sobre a diferença entre doar para o partido do Executivo e contribuir para a oposição. Por outro lado, a variável coal3_doa, que estima a interação entre doar para o restante da coalizão e para a oposição é significativa em ambos os períodos, pré-eleitoral e pós-eleitoral. No entanto, apenas o valor estimado no período antes das eleições é expressivo. Segundo o Gráfico 6, o valor estimado sofre grande variação conforme o valor doado aumenta, chegando a aproximadamente R 140 milhões. De acordo com o Gráfico 7, após as eleições o retorno contratual recebido pelos maiores doadores não ultrapassa $\mathrm{R} \$ 70$ mil montante bem inferior ao financiamento concedido pelas empresas.

Quando significativas, as variáveis independentes dos modelos antes das eleições têm efeitos mínimos muito superiores quando comparadas ao período pós-eleitoral. E mais importante, os testes empreendidos após as eleições indicam que o retorno contratual não cobre o investimento das empresas doadoras.

No entanto, essa comparação deve ser analisada com cautela. Como se tratam de estimadores mínimos, nada garante que o viés positivo no período pós-eleitoral possa ser grande suficiente para aproximá-los dos valores estimados no período anterior às eleições. Antes de eliminar esta expectativa, o presente estudo buscou ressaltar a importância da hipótese concorrente, geralmente negligenciada pela literatura e por grande parte da opinião pública, segundo a qual acordos nascem e findam antes do próximo mandato.

\section{Conclusões}

O presente trabalho buscou analisar principalmente se as empresas que fazem doações aos partidos que integram a coalizão governista recebem valores contratuais mais elevados. E, de modo exploratório, também questionou se as empresas doam como forma de investimento futuro, ou se as doações são

Gráfico 5 - Valor contratual recebido por doadores do partido do Executivo e do restante da coalizão antes e após às eleições

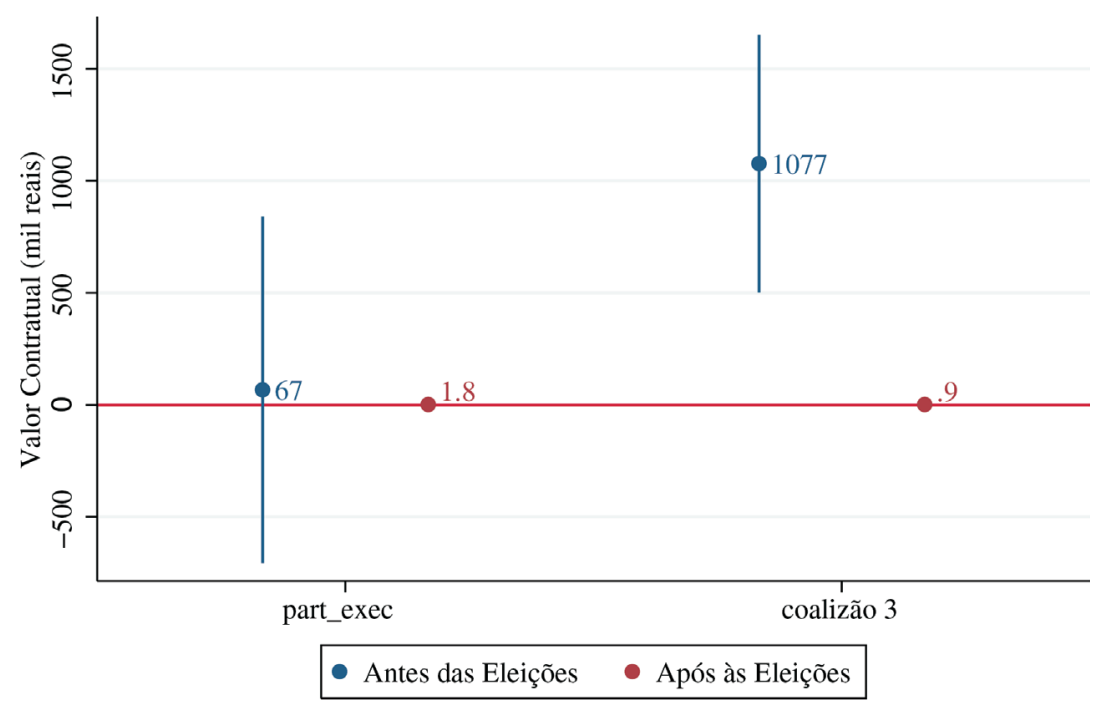

Fonte: Elaboração própria.

Doadores do partido do Executivo (part_exec) 
Gráfico 6 - Efeito de doar para a coalizão com exceção do partido do Executivo antes das eleições

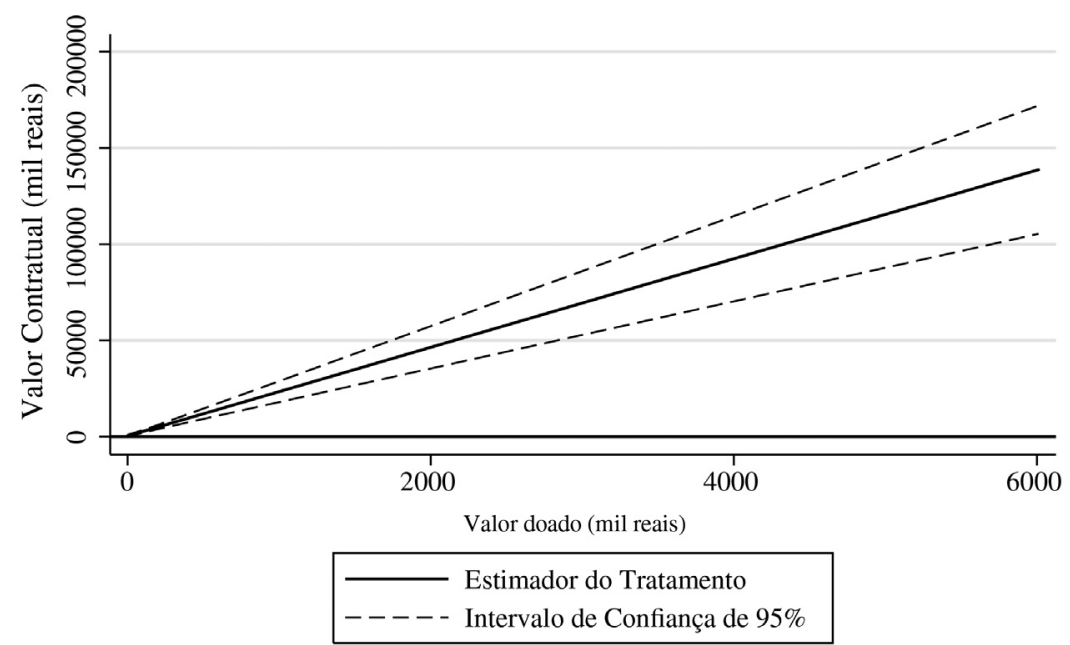

Fonte: Elaboração própria.

Gráfico 7 - Efeito de doar para a coalizão com exceção do partido do Executivo após às eleições

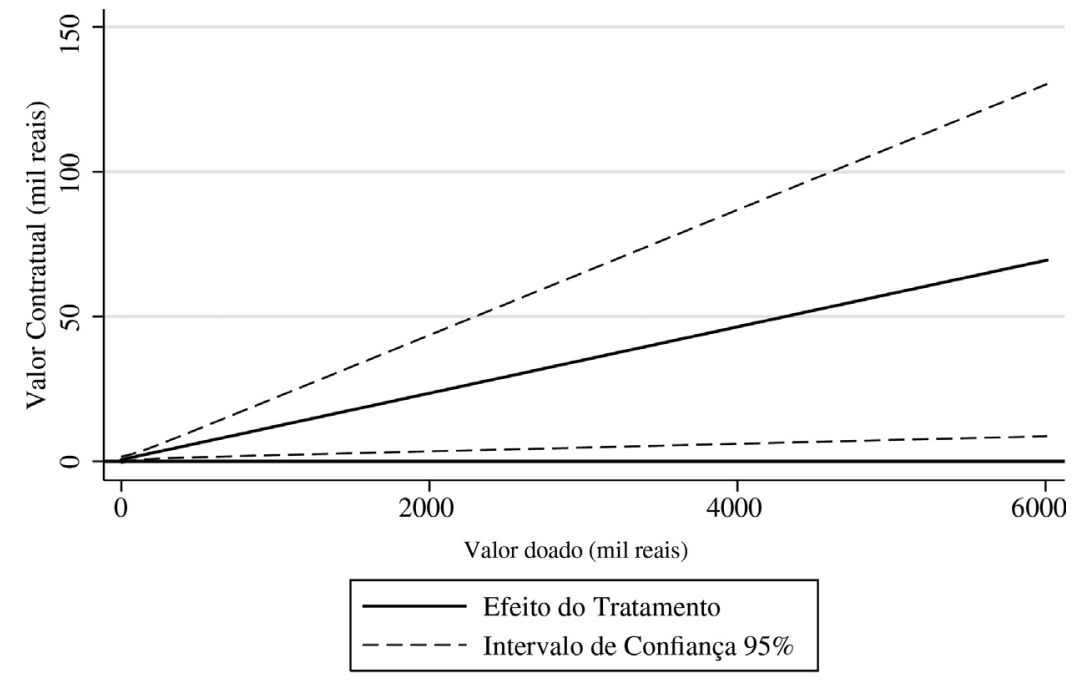

Fonte: Elaboração própria.

creditadas em troca da obtenção de valores contratuais antes das eleições. Afinal, aparentemente as empresas não contam com nenhum mecanismo para forçar atores políticos a recompensá-las no próximo mandato.

Os modelos que analisam o retorno contratual das empresas após as eleições apresentam estimadores muito baixos, o que levanta a suspeita de que as empresas não doam como forma de investimento futuro. Em outras palavras, a recompensa contratual não compensa a preferência de investir em integrantes da coalizão. 
Os modelos que testam diferenças contratuais antes das eleições apresentam estimadores mínimos mais expressivos. Doar para partidos da coalizão governista significa ter obtido, em média, um retorno contratual mínimo de $\mathrm{R} \$ 800$ milhões a mais que os doadores da oposição (Tabela 1). Impressiona também a diferença de valores obtidos por empresas que doaram para ambos os lados. Essas empresas receberam em média $\mathrm{R} \$ 7$ bilhões a mais em relação aos doadores exclusivos da oposição (Tabela 2). Não foi possível afirmar que doadores do partido do chefe do Executivo recebem valores contratuais maiores que os financiadores da oposição, dado à baixa significância estatística (Tabela 3).

Os resultados apresentados estão em consonância com a hipótese defendida neste trabalho, segundo a qual acordos, quando estabelecidos, são cumpridos antes das eleições. Como salientado anteriormente, devido ao viés positivo, não é possível desprezar a hipótese concorrente defendida pela literatura, de que contribuições geram retornos contratuais no próximo mandato (Arvate, Barbosa \& Fuzitani 2013; Boas, Hidalgo \& Richardson 2014; Oliveira \& Araújo 2013). Entretanto, a presente análise indica que ambas as hipóteses merecem ser investigadas com igual importância.

Outra contribuição importante foi elaborar uma estratégia analítica capaz de inserir a dinâmica partidária nos testes empíricos. Estudos futuros podem empregar novos modelos que evitem viés sobre o tratamento, mas terão que lidar com as doações encaminhadas diretamente aos partidos (comitês e diretórios), valores estes que representam o maior volume de contribuições para a campanha.

Thiago do Nascimento Fonseca (thiago.nascimento.fonseca@usp.br) é Doutorando em Ciência Política pela Universidade de São Paulo (USP). Vínculo Institucional: Departamento de Ciência Política, USP, São Paulo, SP, Brasil.

\section{Referências}

Ansolabehere, S.; Figueiredo, J. \& Snyder J., 2003. Why is There So Little Money in U.S. Politics? Journal of Economic Perspective, 17(1), pp.105-130. DOI: 10.3386/w9409

Araújo, G.B., 2008. O déficit entre acordado e realizado no Mercosul. Dissertação de Mestrado. São Paulo: Universidade de São Paulo.

Arvate, P.; Barbosa, K. \& Fuzitani, E., 2013. Campaign Donation and Government Contracts in Brazilian States. Working Paper, 7. São Paulo School of Economics.

Bronars, S. \& Lott, J.R., 1997. Do Campaign Donations Alter How a Politician Votes? Or, Do Donors Support Candidates Who Value the Same Things that They Do? The Journal of Law and Economics, 40(2), pp.317-350. DOI: 10.1086/467375

Boas, T.; Hidalgo, F. \& Richardson, N., 2014. The Spoils of Victory: Campaign Donations and Government Contracts in Brazil. Working Paper, 379. Boston University.

Claessens, S.C.; Feijen, E. \& Laeven, L., 2008. Political Connections and Preferential Access to Finance: The Role of Campaign Contributions. Journal of Financial Economics, 88(2008), pp.554-580. DOI: 10.1016/j.jfineco.2006.11.003

Gonçalves, M.P., 2011. Financiamento político e benefícios tributários: uma análise da atuação de setores contemplados com benefícios tributários no financiamento de campanhas eleitorais (2003-2010). In 35 Encontro da Anpocs. Caxambu.

Jayachandran, S., 2004. The Jeffords Effect. University of Berkeley. Digit. Disponível em: http://www.econ.ucla.edu/people/papers/Jayachandran/Jayachandran297.pdf. Acesso em: 11 fev. 2017.

Lazzarini, S.G.; Musacchio, A.; Bandeira-de-Mello, R. \& Marcon, R., 2011. What Do Development Banks Do? Evidence from Brazil, 2002-2009. Working Paper, 12. Harvard Business School.

Mancuso, W.P., 2015. Investimento eleitoral no Brasil: balanço da literatura (2001-2012) e agenda de pesquisa. Revista de Sociologia e Política, 23(54), pp.155-183. DOI: 10.1590/1678-987315235409

Mello, R.B. \& Marcon, R., 2005. Unpacking Firm Effects: Modeling Political Alliances in Variance Decomposition of Firm Performance in Turbulent Environments. Brazilian Administration Review, 2(1), pp.21-37. DOI: 10.1590/s1807-76922005000100003

Mezzarana, F.S., 2011. Poder econômico na política: a influência dos financiadores de campanha na atuação parlamentar. Monografia. São Paulo: Universidade de São Paulo.

Oliveira, A.J.S.N \& Araújo, G.B., 2013. Doações de Campanha para Deputados Federais Influenciam a Alocação Posterior de Contratos Públicos? A eleição de 2006 e o interstício 2008-2010. In $37^{\circ}$ Encontro Anual da Anpocs. Águas de Lindóia. 
Rocha, D., 2011. Relações entre dispêndios do BNDES e financiamento eleitoral no governo Lula: uma análise empírica. In $35^{\circ}$ Encontro da Anpocs. Caxambu.

Santos et al., 2014. Financiamento de campanha e apoio parlamentar à Agenda Legislativa da Indústria na Câmara dos Deputados. In IX Encontro da ABCP. Brasília.

Welch, W.P., 1982. Campaign Contributions and Legislative Voting: Milk Money and Dairy Price Supports. The Western Political Quarterly, 35(4), pp.478-495. DOI: 10.2307/447336

Wooldredge, J.M., 2002. Introductory Econometrics: A Modern Approach. Mason: South-Western. 
Does Campaign Donation Results Future Contracts Returns? An Analysis about Contractual Values Received to Companies before and after Elections

\begin{abstract}
This paper aims to investigate whether the companies that carry out donations to the federal government coalition parties receive higher contract values, before or after the elections. From 2006 campaign donations on the Superior Electoral Tribunal (TSE) data and contractual amounts of the Transparency Portal of the Federal Government, it was estimated the minimum effect to donate to the coalition members on contractual amounts. Although the estimators contain selection bias due to missed and unobserved variables, the bias expectation is positive due to a positive correlation between the dependent variable and treatment, on one hand, and between treatment and omitted variables on the other. This means it is possible to estimate the minimal effect of giveaway to the coalition on contractual returns. The effect on contractual returns after the elections is very low, but the contractual amounts received by companies before the elections are associated with donations expressively. In addition, it is not possible to state that the Chief Executive Party donors receive major contracts in relation to the opposition financiers. In short, if there is a pact between businesses and members of the coalition, the agreements are established and fulfilled before the elections.
\end{abstract}

KEYWORDS: electoral financing; elections; coalition government; electoral campaigns, government procurement.

This is an Open Access article distributed under the terms of the Creative Commons Attribution Non-Commercial License which permits unrestricted non-commercial use, distribution, and reproduction in any medium provided the original work is properly cited. 